\title{
Parents' Use of Digital Literacies to Support their Children with Disabilities in Online Learning Environments
}

\author{
Mary Frances Rice \\ University of New Mexico \\ Kelsey R. Ortiz \\ University of Kansas
}

\begin{abstract}
An emerging research base has highlighted various roles and responsibilities that parents of students with disabilities accept when they enroll their children in online schools. Since finding and using online texts and using various programs and applications that require search and evaluation skills to do work are typical for online learning, it follows that part of parent responsibilities in many families might involve using basic technological literacies or even more advanced digital ones. To focus on the range of technological literacies that parents employ, researchers gathered self-report data from parents about how they engage with online education technologies while working with their children with disabilities. Interviews with $(n=32)$ parents across six states in the West, Midwest, and Southern United States revealed that parents employ various skills with a specific set of purposes in mind. Literacies were used to (a) perform basic technological computing tasks, (b) evaluate information to supplement existing instructional materials, and (c) communicate with the school about children's needs. Reported purposes for using these skills emerged as (a) instructing, (b) monitoring, (c) advocating, and (d) learning school expectations. Implications of this study include the potential for literacy-based approaches to parent preparation for supporting vulnerable children in online settings.
\end{abstract}

Keywords: virtual schools, parent roles in virtual school, K-12 online learning, students with disabilities, technology skills, digital literacies, technological literacies

Rice, M. F. \& Ortiz, K. R. (2021). Parents' use of technological literacies to support their children with disabilities in online learning environments. Online Learning, 25(3).208-229. doi:10.24059/olj.v25i3.2407 
K-12 student enrollment in fully online learning schools, programs, and courses enjoyed a steady 6\% annual growth since 2009 (Digital Learning Collaborative, 2019). For students with disabilities, pre-pandemic state prevalence estimates ranged from $6 \%$ to $25 \%$ (East et al., 2016). In fact, the number of children who were being educated in online environments and who qualified for special education services under the Individuals with Disabilities in Education Act (IDEA 2004) has been steadily increasing alongside the general education population (Molnar et al., 2015). Additional increases in student enrollment in online environments, including enrollments for students with disabilities, may continue to occur while traditional public schools make adjustments to scheduling and delivery modes associated with the COVID-19 pandemic. Also, some families that became familiar with learning online during the pandemic might decide to become full-time or part-time online school students, even after school buildings fully reopen.

Once children are enrolled in fully online schools, parents typically assume extensive responsibilities for helping children move through their coursework (Alcena, 2014; Black, 2009; Borup, 2016; Borup et. al 2013; Borup et al., 2015). However, previous research has documented that the parents of students with disabilities are given and expect to accept even greater demands on their time and skills to support their children in online schools (Rice \& Carter, 2015, Rice, et. al., 2019). Further, previous research has documented the uneven access parents have to support for their roles as on-site mentors within online schools (Ingersoll et al., 2017; Ortiz et al., 2017). None of this research has specifically addressed these roles with reference to the technological knowledge and skills that parents have or need. Instead, discourse has focused on parents as not providing enough help or providing too much (Black, 2009; Rice et al., 2017). The result is that schools and parents are vulnerable to being confused about what they can and should do for children versus what the schools should provide in terms of support (Rice \& Deschaine, 2021). This is especially important where students with disabilities are concerned because they have rights to services in the United States and many other countries (IDEA, 2004; Márton et al., 2013). Many of these skills are grounded in practices associated with various types of literacies that are becoming part of everyday life in a digital world (e.g., using and producing digital texts, finding and evaluating information, navigating applications) (Martzoukou \& Abdi, 2017). These literacies serve larger goals of acquiring and using cultural capital (Bourdieu, 1986). Rethinking these efforts as technological, even digital literacies might help educators in online environments to conceptualize equitable support for parents in mentoring their children because they offer an alternative to deficit conversations where parents are incapable or do not want to help.

\section{Research Questions}

1. What technological and/or digital literacies do parents report using while supporting online schooling for their children with disabilities?

2. What purposes to do parents cite for using these literacies in relationship to their roles in supporting their children?

\section{Theoretical Framing for Technological Skills as Digital Literacies}

Literate activity is situated in social goals and values (Street, 1984). These goals and values are associated with the desirable habits and are reflected as cultural capital (Bourdieu, 1986). In fact, literacies have been described as the means by which individuals, communities, and societies gather, preserve, and express their capital (Gee, Hull, \& Lanskshear, 1997; Luke, 2003). To this point, Kellner (2000) offered the following definition: 
'Literacy' in my conception comprises gaining competencies involved in effectively using socially constructed forms of communication and representation. Learning literacies involves attaining competencies in practices in contexts that are governed by rules and conventions. Literacies are socially constructed in educational, governmental, and cultural practices involved in various institutional discourses and practices. Literacies evolve and shift in response to social and cultural change and the interests of elites who control hegemonic institutions. (p. 197)

In the digital context, literacies have undergone a transformation from habits and practices associated with typing and attaching files to more sophisticated integration of finding, sorting, evaluating, designing, and critiquing (Martzoukou \& Abdi, 2017). These so-called higher order skills are necessary because they more efficiently do the work of aggregating and maintaining capital necessary to retain group viability.

To further the conception of technological skills as literacies, this study drew on Martin and Grudziecki's (2006) work to classify digital literacies. These scholars argued that digital literacies could be distinguished as (1) computer information technology literacies, (2) technological literacies, (3) information literacies, and (4) communication literacies. These definitions have some overlap in meaning but provide a foundation for thinking about how technological skills have been previously articulated in scholarship as types of literacies.

Computer information technology literacy is concerned with basic computing tasks, such as typing and organizing files. Keywords for this conception include access, manage, integrate, and evaluate information, construct new knowledge, and communicate with others to participate effectively (van Jooligan, 2003; Dakers, 2006).

Technological literacies is an open term with two opposite approaches. The first focuses on skills-based vocational skills for computing. The second focuses on critical, constructivist perspectives that highlight the social and political consequences of technology use (Dakers, 2006; Kress, 2003).

Information literacies acknowledges that the internet has vast amounts of information that users must evaluate and use to make meaning. Primary skills to make sense of this information include recognizing a need for information, identifying what information will help fill the need, locating the information, comparing and evaluating information, organizing and communicating information, and finally synthesizing information, even producing more information as a contribution (Cook, 2018; Martin \& Rader, 2003; Webber \& Johnston, 2017).

Communications literacies. While communication has always been important, technologies have enabled increased digitally supported communication. However, the advent of digital systems that offer instant communication to one or many, requires users to be more aware of the nature and implications what they communicate and how they do it.

\section{Reviewing Literature on Parent Involvement}

Parent involvement in children's education has been theorized in research for in-person settings, online settings, and with various populations, including students with disabilities. A brief review of key ideas from these research areas appears below. While there have been some efforts to understand parent work in the context of capital (Bourdieu, 1986) for traditional inperson schooling, strong connections to capital and concomitant linkages to literacies in parent work in online schooling have not yet been made. 


\section{Traditional Parent Involvement in Education}

Parent involvement for fully in-person educational settings has considered the perspectives of individual parents' beliefs and motivations, the values and goals of the community, and the mission and desires of the school. Where parent involvement has been theorized, the dominant theory has been that schools operate to assist in the transmission of cultural capital as a set of desired aesthetics, traits, knowledge, and habits to future generations (Bourdieu, 1986; Yamauchi et al, 2017). In various models of parent involvement, the goal is to leverage the cultural capital of parents who are regarded to possess it and share the capital with parents who are not. Children can acquire the capital from school, usually to the end goal of functioning as human capital, or workers (Anyon, 1980). Parents from working class backgrounds, who represent racial, ethnic, gender, or linguistic diversity, or who have different physical, emotional, and neurological abilities are not usually the parents regarded to possess cultural capital (Auerbach, 2011). In these capital-focused models, parent contributions to education are supposed to support the goals and aims of the school and what counts as involvement is often distilled to a narrow range of activities that the school closely monitors (e.g., parent-teacher conference attendance) (Epstein, 2011; Hoover-Dempsey \& Sandler, 1995, 2005).

The problem with centering the educational experience on school and the capital it supposedly provides is that it fails to acknowledge important activities that children could do outside of school that are economically important and critical to the identities of families and their members (Moll et al., 1992). Centering school also sets up a power structure where learning must be attained in school settings in a school-ish way (e.g., taking notes) (Anyon, 1980). Even where schools have acknowledged that some families have strong networks, skills, habits, and literacies, the more usual approach has been for schools to determine that some families have the desired traits and some do not (Baquedano-Lopez et al., 2013).

In online educational settings, instructional materials and assignments are provided by schools, but students engage in learning away from the locus of power (e.g., the school building). This arrangement had potential for such power balances to be disrupted. However, there was also the potential that school could impinge on home life to a greater degree. This greater encroachment could come as family life becomes swallowed up in doing schoolwork. Under such circumstances, any time, any place learning leads to doing school assignments all the time, every place. Such disruptions of family life were the basis of some parent complaints about remote online learning during the COVID-19 pandemic-related school building closures (Dong et al., 2020). Parents felt that they were spending large amounts of time advancing the schools' agenda and they were unsure of what the benefits were to the children.

\section{Parent Involvement in Online Learning}

Parent work in online learning and the home-school balance while participating in online school opportunities was identified more than 20 years ago as an issue that needed attention (Litke, 1998; Black et al., 2008; Black, 2009). In these early studies, it was noted that parents were assuming roles that would traditionally belong to teachers, such as making sure that students turned in assignments.

Litke (1998) argued that increased direct parent involvement in education must be a positive development, but Black (2009) found that parents who were very involved in children's work did not have children who were performing better. There are a number of possibilities for why this might be the case. One possibility might have been that parents who have children who are doing well do not need to intervene and therefore, they do not. Only parents with children 
who are struggling, notice the struggle and attempt to help. Heavy parent involvement might also send a message to children that their parents do not have confidence in them, which may lessen their motivation. Heavily involved parents might also be doing some of the work for the child on some assignments and leaving children to do other ones, resulting in uneven performance. Another possibility is that parents who are inclined to intervene are unable to leverage digital literacies and learning skills in ways that translate to school success.

Previous research on parent work in online learning has yielded important findings implying that parents use what are recognizable as digital literacies to help their children. Sorensen (2012) identified organizing learning as a major parental responsibility, which suggested literacy skills associated with calendaring, file sorting, and workflow that probably extended online. Such skills are also recognizable as forms of capital required to attain and retain employment opportunities (Bourdieu, 1986; McLennan, 1967). In another interview study with 10 parents tracking parent involvement, Borup et al., (2015) found parents engaged in five major types of job activities to support their children that all mirror job responsibilities: (1) facilitating interaction with school officials (here, operating as supervisors), (2) advising and mentoring children (here, operating as subordinates), (3) organizing the learning as a multi-step project, (4) monitoring and motivating engagement with the child subordinates, and (5) instructing the children as subordinates. Many of these activities that are essential for clerical positions might have common threads with some responsibilities of parenthood in general, but they take on new meaning or intensify in online schools. For example, teaching children how to fix a wagon or a set a table for a family dinner, or even providing instruction for homework might be typical in many households. However, just because a parent might know how to assist children with tasks, that does not mean they have the stamina to supervise formal learning online during many hours during the day for most of the days of the week. Also, just because parents may have certain job skills for their job, that does not mean they have the time, interest, or ability to automatically translate them into support for their children's learning.

Prior to the COVID-19 pandemic, Borup (2016) used teacher surveys and interviews to learn about teacher perceptions of parent involvement in virtual charter schools. In the 2016 study, teachers reported similar findings to what parents had reported in 2015 (Borup et al., 2015). While teachers expressed gratitude for some of these types of support, they also perceived that some parents were overly engaged in certain types of learning activities, meaning that they were providing too much assistance. Teachers were most complimentary of parents' efforts to monitor assignment completion and communicate teacher expectations to children, reflective of a middle management role where the teachers are the higher-level supervisors. When students were asked about their interactions with parents and their perception of the support they received from parents, students reported appreciation for parent efforts to assist them by providing explanations as the job-related tasks of monitoring and scheduling (Borup et al., 2013).

To learn more about how schools constructed parent roles in online schools, Rice (2015) analyzed testimonials from online schools directed at parents as potential customers. These testimonials characterized parents as instigators of online school enrollment, as well as organizers of schedules and providers of time and space to work online. The major plotline in these testimonials focused on being in a fallen state regarding the child's education. Finding fully online learning alleviated the tension and subdued all anxiety about the child's learning. 
Other than organizing, the testimonials did not feature other aspects of parent work highlighted in previous research. Further, the testimonials did not explicitly highlight digital literacies, but instead suggested that the learning would come right to the child and parent interactions with children around schooling would be idyllic and pleasant.

\section{Parent Involvement in Online Schooling When Children Have Disabilities}

There has also been research on parent work in online learning that is specific to students with disabilities. Findings from these studies have highlighted how parents of children with disabilities are also expected to enact job tasks as a demonstration of capital. For example, Rice \& Carter (2015) studied online educators and found that teachers and administrators engaged in extensive monitoring of students with disabilities to make sure they were submitting work. Further, fully online educators desired parent assistance in monitoring and in making sure that students contacted them regularly. Again, this monitoring was implicitly technologically-related in its requirement to use a learning management system, but not explicit about the digital literacies parents would need (Ortiz et al., 2017).

Researchers at the Center on Online Learning and Students with Disabilities (COLSD) also conducted several additional studies of parent work (Basham et al., 2015). Studies of parent work within this center focused on parental role construction, disability service transition, and social and emotional support for parents and students with disabilities when they moved online. These researchers found that parents described their roles as educators, medical aides, reward managers, and executive function directors for students. These findings centered on executive function where parents narrated the need for digital literacies in organizing student work (Rice et al., 2017).

Researchers have also found that parents felt pressure to assume these roles because transition services for students' Individualized Educational Programs (IEPs) were inconsistent in their quality (Smith et al., 2017). Some parents did have positive experiences, but other parents reported that their children lost access to many of their special education services, and that fully online schools refused to provide supplementary services and support guaranteed per U.S. law (IDEA, 2004). Even when parents reported receiving some support and believed they had positive relationships with school officials, they seemed to be misinformed about the services they were receiving. For example, when researchers inquired about access to assistive technologies, parents would affirm they had these. When asked to name the assistive technologies they had received, parents were unable to say anything specific. Moreover, they did not know where to go- online or offline to find information about assistive technologies.

More recently, Rice et al. (2019) documented the difficulties of a foster parents working to support a child with multiple disabilities in a virtual school. The foster mother in this study was in her 60s and two children with disabilities in her home. The parent reported extensive efforts to contact school officials and communicate her child's needs to them. When those queries were unmet, she resorted to doing most of the instruction for her foster son on her own. As part of this work, she described using specific information literacies, such as finding YouTube videos for her son and using online spreadsheets to make daily schedules. She did not receive instruction on how to do these from the online school. Instead, she seemed to be drawing on skills she brought with her to the situation through work and her university education.

Although there are negative reports made by parents about working with their children online, many parents of students with disabilities continue to affirm their desire to be at an online school rather than a traditional one. In Beck, et al.,'s (2014) study, parents of students with disabilities were more positive than parents of children without disabilities. Also, (Rice et al., 
2017) found this to be the case among parents they interviewed across multiple states. These parents believed that if their children could not succeed in a fully online school, they may not find success anywhere, since traditional schooling experiences had been poor also. Importantly, these parents also believed that their children with disabilities had educational and personal needs that others cannot understand or do not want to, and they enjoyed the opportunity to work with their children out of the immediate presence of school officials (Rice et al., 2017; Rice et al., 2019). Other researchers have had similar findings (Tonks et al., 2021). Drawing on a study of parents of children with disabilities who enrolled the children in a virtual school in California, Schultz (2019) wrote:

[P] arents of students with disabilities chose a full-time virtual charter school for their children due to push factors related to their previous school. Parents seemed most interested in being able to individualize education for their child, have a flexible schedule, and be able to instill their values in their children by educating them in the household. (p. 75)

Thus, it seems that parents are willing to use a variety of literacies and subordinate to school expectations if it means they can remain in an online school with some autonomy and be successful.

As the COVID-19 pandemic set in, researchers were questioning the level to which students with disabilities were truly included in online learning environments and whether typical practices for supporting parents of children with disabilities in online learning were sufficient (Rice \& Deschaine, 2021; Rice \& Ortiz, 2020). Early research findings from studies and district-sponsored questionnaires conducted during the COVID-19 pandemic showed varying responses to supporting remote online education. Parents in Dong, et al.'s study, (2020) reported spending large amounts of time supporting their children, but they could not tell what their children had learned. In district surveys from the U.S., parents were generally positive. However, some parents voiced concerns that were grounded in literacies, such as keeping track of different websites and digital tools, managing timing for video conferences with multiple children, and helping their children keep pace with what was perceived as a higher workload than before the pandemic (Gwinnet County Public Schools, 2020; Parsippany-Troy Township Schools, 2020). These challenges were more acute for parents of children with disabilities.

What we do not yet know is what digital literacies parents believe they have for providing support in these domains from previous research (facilitating interaction with school officials, advising and mentoring, organizing, monitoring and motivating student engagement, and instructing). We also do not know parents' purposes for using these literacies to work with their children. To gain additional understanding on these topics, we engaged in the current study.

\section{Methodology}

In this study interviews were collected, and the content was analyzed to uncover themes (Boeije, 2010; Birks \& Mills, 2015; Trainor, 2013). These interviews occurred with 32 parents of children with disabilities in online schools.

\section{Participating Parents}

Parents from nine different programs in six states participated in this study (California, Colorado, Georgia, North Carolina, Utah, Wisconsin). Each of these states has multiple online school providers. Parents in this study were invited to the study in two ways. The first way was 
through invitation from a national parent advocacy network for children with disabilities. From this invitation, 19 parents agreed to an interview.

The second way was through an invitation at the end of a survey designed at a technical service center and distributed to parents directly through online charter schools. Thirteen parents who responded to this survey agreed to participate in an interview. Parents had a range of experience in virtual schools (from one semester to three years). The average experience level was 2 years. Most of the parents identified as biological mothers of the children $(n=28)$, which a few grandmothers in parenting roles $(n=3)$ and one foster parent (mother). Parent/grandparents reported ages ranged from 28 to 70, with a mean age of 36. Reported household income ranged from $\$ 28,000 /$ year to $\$ 120,000 /$ year. However, most parents reported a household income between $\$ 40,000$ to $\$ 65,000$. Table 1 summarizes demographic information.

\section{Table 1}

\section{Participant Information}

Category

Age

Children's primary disability**

Experience with online schooling

Household income*

Race/Ethnicity*

Role

State of residence

**Note: Some parents had more than 1 child with a disability, resulting in $\mathrm{n}>32$.

Types N N

Under 30

$30-40-25$

$40-50$
+50

Autism Spectrum Disorder $\quad 11$

Attentional Disorder $\quad 10$

Emotional/Behavioral Disorder 2

Other Health Impairment 6

Specific Learning Disability 4

Speech Language Disorder 3

one year 4

2 years 14

3 years 3

3 or more years

$\$ 20,000-\$ 30,000 /$ year 5

$\$ 30,000-\$ 40,000 /$ year 4

$\$ 40,000-\$ 50,000 /$ year 6

$\$ 50,000-\$ 60,000 /$ year $\quad 8$

$\$ 60,000-\$ 70,000 /$ year

White, non-Hispanic

Black, non-Hispanic 2

Black, Hispanic 1

Mixed Race 3

Mother 28

Grandmother 3

Foster mother

California 4

Colorado 2

Georgia 5

North Carolina $\quad 8$

Utah 3

Wisconsin 10

*Note: Some participants declined to answer some questions resulting in $\mathrm{n}<32$. 
In addition, while 10 parents reported having bachelor's degrees and one had a master's degree, the rest had some college without a degree or none at all. Paid employment for participating parents in the study included educators $(n=2)$, health care workers $(n=3)$, business owners $(n=3)$, and customer service representatives $(n=4)$. However, most were not currently working for pay $(n=20)$. Permission from a university ethics board was obtained for conducting this research and privacy and confidentiality was preserved in accordance with directives from the ethics board.

\title{
Data Collection
}

Two researchers conducted interviews with parents. These interviews were semistructured; questions were asked using a protocol, but interviewers solicited elaboration when it was relevant to contextualizing a response or further illuminating research questions (Brinkman \& Kvale, 2018). The interview protocol was based on previous research conducted with parents of students with disabilities by the Center on Online Learning and Students with Disabilities but was modified to include more information about digital literacies (Basham et al., 2015). The interview protocol included several questions related to demographics. These were followed by questions about the children's disabilities and how the disability affected learning, as well as the support and services they were receiving. Next, interviewers and parents discussed labor roles, current daily routines, and resources accessed apart from the school. After establishing this context, we asked them about the technologies they used and had them refer to previous responses to make connections. The interview protocol appears as Table 2.

\section{Table 2}

\author{
Topics and Questions for Interviews \\ Topic \\ Questions \\ Demographics What is your age? \\ What are your children's ages? \\ How do you and your family identify socially (race, ethnicity, gender)? \\ What are the educational attainments of the adults in the household? \\ What types of work for pay do adults in this household do? \\ Can you give an estimate of your yearly household income? \\ What are your children's ages? \\ Disability $\quad$ For the children who have disabilities, what are the disabilities? \\ information How was this disability identified? \\ What services and supports does the child receive? \\ Labor roles How do the various adults in your household or social circle provide support to the children \\ who are learning online? \\ Routines Can you describe a typical day learning online in your household? \\ Can you describe an exceptionally challenging day? \\ How did you meet the challenges you experienced? \\ Technologies How would you rate your skill level with using technologies to support your child's learning? \\ Can you describe the technological skills that you use most often? \\ For what purposes have you used technological skills to support your children's learning? \\ How is what you do with technologies for your children related to what you have done in a \\ job situation or that you think you might do? \\ Do you think that your literacies or fluencies with technologies helps you support your child? \\ Can you give an example?
}


The set of questions was designed to provide multiple opportunities for parents to describe literacies they used and purposes although questions about support began and general ones and became increasingly more targeted to literacies. This was done to make parents feel more confident. Interviewers thought asking about literacies immediately would be intimidating, confusing, or may even sound like shaming to some parents.

Interviews were conducted and recorded using web conferencing applications. The applications generated automatic transcriptions. Interviews lasted between one and two hours. The variation in time was due to the number of children in the family, the extent to which the parents deigned to share information, the length of time parents had spent as on-site mentors in online learning, and potentially their overall level of comfort with being interviewed.

\section{Data Analysis}

To learn from the interviews, the researchers who conducted the interviews coded them in three phases: open coding, axial coding, and selective coding (Boeije, 2010; Birks \& Mills, 2015). During the open coding phase, researchers read the data, highlighted meaningful information, and created initial codes. The meaningful information was targeted based on the research questions about parents' use of digital literacies and the purposes behind their uses.

During axial coding, the relationships between the codes were developed into a hierarchical structure. Instead of calculating inter-rater reliability, the researchers shared their codes and negotiated them (Garrison et al., 2006). In addition to open and axial coding, researchers sought to make connections between codes to analyze the content (Krippendorff, 2018). In considering connections, core themes not only appear frequently; they are also connected to other codes (Boeije, 2010). This was particularly important since we found that parents descriptions of their uses of digital literacies were often directly tied to their rationales. This was also true because our interview methodology focused on connection-making. It was not possible, then, to report the answers to the research questions sequentially (RQ1 report followed by RQ2 report). Instead, the connections researchers made by mapping codes and subcodes yielded themes where use and purpose were linked. The mapping was done by researchers through drawing codes and drawing connections and then checking back with the data. The coding scheme yielded three major themes around technological literacies (basic, informational, and communication) with 3-4 subthemes for each.

\section{Findings}

Parents reported using basic computing skills to support their children. They also reported using information literacies to learn on the internet and various communications tools. Each of these themes and their accompanying rationales is discussed below.

\section{Basic Computer Information Technology Literacies}

All parents in this study $(\mathrm{n}=32)$ reported a need for basic computer information technology skills to support their children with disabilities. These skills were used for organizing learning, troubleshooting, and advocacy efforts, particularly advocacy that enhanced accessibility to the curriculum.

Organizing learning. These skills came in the form of using basic technological applications and doing rote tasks like turning logging onto the internet. The parents often paired their discussion of technical literacies with efforts to organize the learning of their children. A parent of a 14-year-old boy with sensory processing disorder offered the following explanation. 
In the brick-and-mortar, you keep your locker clean, right? Now in online learning we work on keeping his desk area clean, having a daily agenda, and using the Google calendar [application]. For his live learning classes, I have him log in 5 minutes ahead and help him to check his email.

This is a parent who has a high school diploma and no further education. High school is the experience from which she can draw. The parent wove traditional organization skills together with basic computing skills (keeping a calendar, opening and responding to email) as part of a plan to help the child learn routines and stay current with his work. Using these technological skills is key to staying organized. The parent reported, based on her own experience, that being organized was the integral to school success and she often made analogies (i.e., the locker) to explain her thinking. It also represents a belief transmitted by schooling the organization, even of something such as the locker is the pathway to success. Logging in early and checking email represent additional attempts to affirm the habits of the school as a workplace for both of them.

Troubleshooting. While being organized and going online early for tasks like email provided a sense of calm for many of the parents, of course, some of the technological skills went toward troubleshooting when technologies failed. Only one parent did not report troubleshooting, in fact. The high-school educated parent of a 12-year-old with autism described one such circumstance and their workaround.

There's a good amount of technical difficulty at times. Whether it's an internet connection or whatever system they use to do the live lessons. I believe it was an Adobe program and sometimes the teacher would get kicked out of the room during the middle of the lesson. It would just go quiet all of a sudden. That happened kind of frequently, which is a little frustrating. After a while we didn't attend the live sessions anymore. We watched the recordings, especially because with math you could pause it and go over it to make sure he understands and then resume. In the live lesson, in real time you couldn't do that.

To account for the technical issues that the parent deemed was beyond her control, she simply stopped attending the synchronous lessons. However, making this decision required the parent to use basic computing skills in accessing the videos, playing them, and then leveraging their affordances to support the teaching she was doing. Keeping the children online and deciding how to use asynchronous materials were critical ways that parents used to keep kids working.

Advocacy. Close to two-thirds of the parents $(n=20)$ were engaging with a more extensive repertoire of technological devices, which required different skills. For example, a parent of a 10-year-old with a rare form of brittle diabetes had to research, purchase, and learn to use a bevy of technological equipment.

Parent: We had to purchase him an enlarged, high-contrast keyboard. The virtual school didn't do it. We had to purchase him extra speakers so that he could hear things better. The school didn't do it. We had to purchase colored overlays for his computer, the school wouldn't do it. They are really refusing assistive technology that has been identified that would help him. 
Interviewer: Those technologies were identified with outside testing?

Parent: Yes. And some of it was identified in the brick-and-mortar school as well. He had an FM transmitter, which showed he needed better speakers. He needed high contrast paper and in brick-and-mortar they would Xerox things on colored paper. Interviewer: The FM system or the contrasting paper, was that in his IEP? Parent: Yeah.

Interviewer: And the virtual school would not provide it? Parent: No.

This parent was doing this work of acquiring various technologies and learning to use them alongside a computer required for virtual learning as a measure of advocacy. The family had the financial resources and a sense of the importance of these assistive technologies, and they went out and found them. These purchases were made so the child could do his work more efficiently. Instead of asking for these from the school, the parent did not feel they were able to advocate with the school; they found it easier to avoid making a plea for supplies and bought their own. This acquisition of one's own work supplies formulated advocacy as something the parent does for the child to make sure they look competent to the school.

\section{Information Literacies}

The parent referenced above did not only have to develop and use skills for coordinating different types of technologies. She also had to go onto the internet, research about these assistive devices and how they worked with computers, conduct price audits, and make arrangements for the items online. More than two-thirds of parents $(n=25)$ reported using informational literacies, such as locating, evaluating, and sharing content found on the internet to work with their children in virtual schools. These information literacies were used to find the virtual school in the first place, and then because parents felt they needed to provide instruction for their children.

School searching. About 25 percent of parents $(n=8)$ were referred to online schools by word of mouth. For example, one participant was referred to a fully online school by the waitstaff at IHOP. A few parents found their way to virtual school because friends, colleagues, or brick-and-mortar school staff referred them. However, most parents $(n=24)$ went through an information search and evaluation process to find the virtual school. One parent described changing from a brick-and-mortar rural school to a rural virtual school because she knew her child was not keeping up with peers.

My son is not very academic, and he wasn't off the average pace of students in the public school. [The school was] giving him a lot of accommodations, and there were people working with him, but I still felt like that he wasn't going to be able to work to his full potential because in a classroom you have to stick to a certain pace. I felt like if we were able to work at home we could work at his pace, and he wouldn't be missing things because they had to move on to the next thing. I specifically looked for a school where he could work at a slower pace.

The parent was able to take her search criteria "a school with a slower pace" and search through various programs. She then identified the online school, contacted a representative, and began moving through the process of enrollment. Besides their criteria, parents needed to find schools that would accept their children. Most parents who described a search process were rejected 
outright from at least one virtual school. One parent who was accepted right away had six children. They were all admitted as students without disabilities, but three of the children were later tested and identified as having speech-related disabilities. Parents with children with severe disabilities were especially vulnerable to being denied enrollment. One parent reported that school officials would ask her to make detailed descriptions of the nature of the child's disability before they would invite her to enroll, citing resource difficulties. Because of difficulties like these, parents' efforts to seek information about online schools were often compromised. Again, the important element is the parent working to make the child look acceptable to the school-to appear that they have the capital and resources necessary, instead of being able to take an orientation where the school assessed their strengths and needs and served them.

Instruction. Parents were much more successful in their use of information seeking literacies after enrollment as they accepted additional responsibilities to provide instruction directly to children apart from what the school was providing. Of 32 parents, only 2 indicated that they did no teaching during their work to support their child. The parent of a 14-year-old with a specific learning disability described her use of information literacies to supplement science curriculum from the virtual school.

Being his teacher, it's all on me if he doesn't learn the things he needs to learn. It would be all my fault. I have to make sure that I prepare his subjects the night before. I look over them to see what we're going to be learning the next day or even that following week, because we have projects. Science projects, for example. I have to find extra videos and stuff to help him learn.

For parents who did consider themselves as having teaching responsibilities, all of them reported searching for additional information on the internet to help them explain concepts or finding additional videos, websites, and so forth that they perceived would be more engaging for the child. Sometimes this engagement was sustained by sounds, lights, games, animation and so forth. Other times, the more engaging resources that parents located were merely texts that were at a lower reading level for a student with low reading skills. Parents did not seem to mind gathering additional resources and making decisions about whether, when, and how to share them with their children. In fact, they often reported feeling success when they did this. Even so, parents felt pressed for time to do this regularly or felt it as acute pressure to ensure their children's learning without support from the school. For them, searching for resources, evaluating them, and deciding what to use added to the burdens they felt in providing instruction. In these conversations, there was no sense that school might provide these resources. Besides, in a model where the child is the worker and the parent is middle management and the teacher is the higher-level supervisor, these parents do what takes to please the supervisor.

\section{Communication Literacies}

The final commonly reported skill for parents were communications tools $(n=19)$. These tools were used to support their children in communicating with peers, for monitoring student progress, and for learning the school's expectations of them.

Peer-to-peer communication. Even in cases where parents are not regraded to have capital, facilitating communication with peers was a reason that 18 of the parents cited for using these technologies. This was actually a more popular reason than communicating with teachers. In fact, older students had regular access to their teacher though messaging systems and they used apart from their parents or they did not engage with teachers at all. 
The parent of an 8-year-old boy with intellectual disabilities and a hearing impairment described her use of communications tools to help her child engage with his teacher and his peers. This parent seemed to be the most advantaged by far in terms of understanding what could and should be done to support students with disabilities because she was also the director of special education at a virtual school.
We kept all the accommodation domains from the original IEP and then shifted those goals for the home setting. We are looking at basic communication-greeting people when someone comes to the home, for example. In addition, my son uses an eye gaze talking device to communicate with people who visit or online. We were able to develop social skills goals as well that included assisting him in interacting with peers through the chat box. We also use emoji. I made sure there are social skills mini lessons where we revisit with the chat box (some students use chat to text features they can use as extensions on a regular chrome book or touch screen chrome book). Parents can also use a touchscreen chrome book for communicating.

This parent was able to name many technology-enhanced strategies for helping her son communicate with his class. Unlike the other parents, this parent had the school provide the technologies and resources. Because that parent understands the school system and is used to having people work for her (not the other way around), she can get what she needs and is under little to no pressure to make her child look acceptable to the school. Because she is regarded as having the acceptable capital, the school has to provide the resources that are acceptable to her and her son.

Progress monitoring. The technologies the parent articulates in the example above were more extensive than those that other students in our study were receiving. Most parents reported that they used the communication tools outside of the child's presence to learn about student progress. Typically, this was done with message systems inside the learning management system, with applications like remind.com. or voice over internet protocols and video conferencing programs. In the following example, a parent of a 17-year-old with an emotional disorder and attention deficit disorder shared how she uses the learning management information often to communicate with teachers and monitor her daughter's progress.

She is in a jigsaw application, which is linked to her teachers separate from me. I just look at the learning management system. I see assignments that are coming due on the gradebook. I work a lot of hours as a nurse. I tell my daughter that she got a bad grade, and she needs to re-do it. The dashboard also shows me how much time she has spent working on the class. I know when she is goofing off and when she is not. It is a great feature to have. The more I hover over her, the more she stresses, so it is good to have a way to look at her progress that is not confrontational with her.

The parent uses the tools to try to avoid over-involvement in her daughter's instruction. This is for two reasons - first, she worked many hours on a rotating schedule as a nurse and cannot be around when her daughter is doing her schoolwork during the day. Second, tension and agitation resulted when the mother asked questions. Communication tools help maintain family harmony since now the mother only has to get involved if there is a serious breach in a steady work pattern. 
School expectations. Finally, parents used communications tools to learn the school's expectations for them. A parent of a 13-year-old with writing and spelling disabilities described the online parent information the received via webinar.

They had an in person or online orientation where you were taught everything about the school, the expectations, the online format, the curriculum and how to use it.

While almost half of the parents in the study reported some form of parent training, usually delivered online, the purpose was often for the school to communicate the information that they wanted the parents to have. There were not as many reciprocal efforts made for the parents to communicate with the school. In fact, in the example above where the parent communication came exclusively through the learning management system, this was suggested by a teacher. That teacher told the mother to stop monitoring of her daughter because the teacher believed it would be better for the daughter, given her emotional challenges. However, this also set up a system where the mother is more likely to receive communication from the school than send it. This incident is also a good illustration of how parents become comfortable with their roles as middle management - where they have a lot of autonomy until the higher-level supervisor (the teacher) gives them a directive. At this point, the parent is supposed to obey, which they often did.

\section{Discussion}

Previous research in virtual school learning has highlighted specific roles for parents. These included (1) facilitating interaction with school officials, (2) advising and mentoring, (3) organizing, (4) monitoring and motivating engagement, and (5) instructing (Borup et al., 2015). In this study, parents' use of technology maps onto these roles very well, probably because they match the capital needed for obtaining and retaining many types of jobs (Ayon, 1980; Bourdieu, 1986). These responsibilities that parents in this study accepted positioned them as middle management supervisors of their children's learning, rather than parents. What made it worth the effort for parents was their purposes in making their children look acceptable to school to support their well-being. With the exception of the highly educated parent, they all accepted the school's expectations as being legitimate; their job was to do what it took to make their children successful in the eyes of the school, even if it meant large amounts of work for them.

These management/supervisor position might be a valued role for some parents, but a burden for others. Particularly during remote learning associated with the COVID-19 pandemic, parents who suddenly became remote online schooling parents, but then lost their jobs might have felt glad to enact work roles at home for the sake of routine. Conversely, they might be resentful at having act like they were at work without being at work and getting paid. Some parents who have jobs where they rank higher than many other employees might also resent a subordinate role.

Parents in this study exhibited a wide range of literacies in helping their children with disabilities access and engaged with the instructional materials provided by the school.

Generally, the parents were able to use the tools and applications that were recommended by the school or that they knew to use from other parts of their lives, such as work or family life (e.g., Google calendar) (Dakers, 2006; Martzoukou \& Abdi, 2017). Parents drew on applications and tools that were already included in their capital (Bourdieu, 1986) many of which came from jobs 
they had or used to have (McLennan, 1967). In cases of limited formal post-higher school education, the high school experience provided capital upon which they could draw.

\section{Implications for Practice}

Parents reported searching for resources and evaluate them. To do this, they used their

personal knowledge of their own children and their sense of what would be helpful them. This is much closer to models of parent involvement that assume all parents have strengths (Auerbach, 2011; Moll et al., 1992). Moreover, parents can be regarded as having digital literacies even when they are not always able to support their children in the ways that schools might prefer (McDougall et al., 2018).

In this study, parents used the learning management systems to communicate (Cook, 2018; Martine \& Rader, 2003; Webber \& Johnston, 2017). However, this communication was usually in one direction-from the school to the parent. This is consistent with previous theorization of schools as being centered on their pursuit of capital distribution and cultural reproduction (Auerbach, 2011; Baquendano-Lopez et al., 2013). The unidirectionality was also present in the parents' descriptions of webinars and other information that some parents in this study were provided. Parents could benefit from more opportunities to communicate with the school, but more importantly, they need more opportunities to share their digital literacies with schools (Baquedano-Lopez, 2013). Specifically, there might be opportunities for parents to selfselect activities to acquire or practice more literacies during interactive opportunities sponsored by the schools.

For parents of students with disabilities, parents used their digital literacies to accommodate, modify, and even compensate for the inadequacy of the instructional materials in needing the child's needs. Moreover, parents' major purpose in engaging with digital literacies was for teaching. This finding is in line with previous research on parents of children with disabilities that has found parents take on roles as instructors because they think other people either cannot or will not meet their children's needs (Rice et al., 2017; Rice et al., 2019). Knowing that parents see themselves and their children in these ways, schools should provide guidance for helping them choose materials and technologies that help parents address issues that matter the most to them. It would also be helpful if schools broke away from their expectation that parents were supposed to advance the schools' agenda as middle management workers. Instead, schools and parents should collaborate to set and meet mutual goals for children's learning.

\section{Implications for Research}

Future research projects should aim to make more detailed descriptions of how parents obtain and use digital literacies for their children's online education. It is also important to take a more critical approach to the expectations laid on parents. Conceptualizing the expectations for them as job skills that are also require certain digital literacies could lead to many studies that carefully examine how these expectations are established, which parents with which job histories and skills accept/reject these responsibilities and under what circumstances, and how parents and schools establish healthy expectational boundaries for one another. Understanding how parents use the technologies they have and gain access to new ones through school and other outlets seems important for ensuring that extant gaps in educational experiences do not grow larger. It also seems important to understand what role literacies play in accessing infrastructure such as high-speed internet and high-quality internet-ready devices, as well as high quality digital instructional materials. The literacies required to access such resources might play important roles in children's online learning success. 
Additional research might also describe how attempts at collaborative projects focused on learning with and from parents about digital literacies can support student achievement and other indicators of high quality experiences. It might also be helpful to learn more about how and whether parents explicitly share these literacies with their children during online learning. Importantly, efforts to support students merely by providing parents more "training" on what the school wants them to do might not be the best approach for trust-building between parents and schools and the long-term success of children.

\section{Limitations}

This study did not use probabilistic sampling or other procedures associated with the positivist paradigm. Therefore, it is not generalizable. What is important about the work is that it offers a basis for learning more about parents' digital literacies when supporting their children with disabilities that could lead to research tools like survey instruments and the development of additional support programs. Also, these findings might inform tools of practice as they highlight the need to learn more about what parents know and are able to do with the technologies that they have access to while supporting their children with disabilities in online schools. These findings are also important for developing initial policy conversations about how to involve parents meaningfully in the education of children with disabilities per IDEA (2004) and how to include thinking about their digital literacies in such conversations.

\section{Conclusion}

This study described the digital literacies that parents $(n=32)$ used in supporting their children with disabilities in virtual schools. This research is valuable to improving the educational experiences of children with disabilities who voluntarily come to these schools as well as children who are directed to online learning in some ratio or form because of the pandemic. Parents with a range of demographic characteristics and experiences were able to use basic technological literacies, information literacies, and communication tools. What needs to be improved for these families is acknowledgement of the literacies that they bring, as well as access to interactive, collaborative, preparation for their roles, even personalized parent preparation based on self-selected familiarity with technologies, e-learning, or some other factor. 


\section{References}

Alcena, F. M. (2014). Parental involvement and its impact on student achievement in Florida virtual school. Distance Learning, 11(2), 25-32.

Auerbach, S. (2011). Conceptualizing leadership for authentic partnerships: A continuum to inspire practice. In S. Auerbach (Ed.), School leadership for authentic family and com-munity partnerships: Research perspectives for transforming practice (pp. 29-52). Routledge.

Baquedano-Lopez, P., Alexander, R. A., \& Hernandez, S. J. (2013). Equity issues in parental and community involvement in schools: What teacher educators need to know. Review of Research in Education, 37(1), 149-182.

Basham, J.D., Stahl, S., Ortiz, K., Rice, M.F., \& Smith, S. (2015). Equity matters: Digital \& online learning for students with disabilities. Center on Online Learning and Students with Disabilities. http://www.centerononlinelearning.res.ku.edu/equity-matters-digital-and-onlinelearning-for-students-with-disabilities/

Beck, D., Egalite, A., \& Maranto, R. (2014). Why they choose and how it goes: Comparing special education and general education cyber student perceptions. Computers \& Education, 76, $70-79$.

Litke, C. D. (1998). Virtual schooling at middle grades: A case study. University of Calgary.

Birks, M., \& Mills, J. (2015). Grounded theory: A practical guide. Sage.

Black, E. W. (2009). An evaluation of family involvements' influence on student achievement in K-12 virtual schooling. [Unpublished dissertation]. The University of Florida, Gainesville, FL. https://www.proquest.com/docview/304883948?pq-origsite=gscholar\&fromopenview=true

Black, E. W., Ferdig, R. E. \& DiPietro, M. (2008). An overview of evaluative instrumentation for virtual high schools. The American Journal of Distance Education, 22(1), 24-45. https://doi.org/10.1080/08923640701713422

Brinkman, S., \& Kvale, S. (2015). InterViews. Sage.

Boeije, H. (2009). Analysis in qualitative research. Sage.

Borup, J. (2016). Teacher perceptions of parent engagement at a cyber high school. Journal of Research on Technology in Education, 48(2), 67-83. https://doi.org/10.1080/15391523.2016.1146560

Borup, J., Graham, C. R., \& Davies, R. S. (2013). The nature of parental interactions in an online charter school. American Journal of Distance Education, 27(1), 40-55. https://doi.org/10.1080/08923647.2013.754271 
Borup, J., Stevens, M. A., \& Waters, L. H. (2015). Parent and student perceptions of parent engagement at a cyber charter high school. Online Learning, 19(5), 69-91.

Brinkman, S., \& Kvale, S. (2015). InterViews. Sage.

Cooke, N. A. (2018). Fake news and alternative facts: Information literacy in a post-truth era. American Library Association.

Dakers, J. (2006). Defining technological literacy. Palgrave Macmillan.

Digital Learning Collaborative. (2019). Snapshot 2019: A review of K-12 online, blended, and digital learning. Evergreen Education Group. https://www.evergreenedgroup.com/keeping-pacereports

Dong, C., Cao, S., \& Li, H. (2020). Young children's online learning during COVID-19 pandemic: Chinese parents' beliefs and attitudes. Children and Youth Services Review, 118, 1-9.

East, T., Mellard, D., Stahl, W., Basham, J., \& Smith, S. (2016). Response to OSEP request regarding the prevalence and experience of student in online instruction: May 25, 2016. Center on Online Learning and Students with Disabilities. University of Kansas. Author.

Epstein, J. L. (2011). School, family, and community partnerships: Preparing educators and improving schools (2nd ed.). Westview Press.

Garrison, D. R., Cleveland-Innes, M., Koole, M., \& Kappelman, J. (2006). Revisiting methodological issues in transcript analysis: Negotiated coding and reliability. The Internet and Higher Education, 9(1), 1-8.

Gee, J. P., Hull, G., \& Lankshear, C. (1997). The new work order. Westview Press.

Gwinnet County Public Schools. (2020). Results from spring 2020 digital learning days survey. Gwinnet County, Georgia. https://publish.gwinnett.k12.ga.us/gcps/wcm/connect/ce9d31bb-377e427c-a3f8-7dd8b943e512/Digital-Learning-Survey-Results-June-18-2020-BOEMeeting.pdf?MOD=AJPERES\&CVID=nbezwrm

Hoover-Dempsey, K. V., \& Sandler, H. M. (1995). Parental involvement in children's education: Why does it make a difference? Review of Educational Research, 67(1), $3-42$.

Hoover-Dempsey, K. V., \& Sandler, H. M. (1997). Why do parents become involved in their children's education? Teachers College Record, 95, 310-331.

Individuals with Disabilities Education Act [IDEA]. (2004). P.L. 108-446, 20 U.S.C. $§ 1400$. 
Ingersoll, B., Shannon, K., Berger, N., Pickard, K., \& Holtz, B. (2017). Self-directed telehealth parent-mediated intervention for children with autism spectrum disorder: Examination of the potential reach and utilization in community settings. Journal of Medical Internet Research, 19(7), e248. dpo: 10.2196/jmir.7484

Kellner, D. (2000). Multiple literacies and critical pedagogies: New paradigms. In P. P. Trifonas (Ed.), In revolutionary pedagogies: Cultural politics, instituting education and the discourse of theory (pp. 196-221), Routledge.

Kress, G. (2003). Literacy in the New Media Age. Routledge.

Krippendorff, K. (2018). Content analysis: An introduction to its methodology. Sage.

Luke, A. (2003). Literacy and the other: A sociological approach to literacy research and policy in multilingual societies. Reading Research Quarterly, 38(1), 132-141.

Martin, A., \& Grudziecki, J. (2006). DigEuLit: Concepts and tools for digital literacy development. Innovation in Teaching and Learning in Information and Computer Sciences, 5(4), 249-267. https://doi.org/10.11120/ital.2006.05040249

Martin, A., \& Rader, R. (2003). Information and IT literacy: Enabling learning in the $21^{\text {st }}$ Century. Facet.

Márton, S. M., Polk, G., \& Fiala, D. R. C. (2013). Convention on the rights of persons with disabilities. Committee on the Rights of Persons with Disabilities, United Nations.

Martzoukou, K., \& Abdi, E. S. (2017). Towards an everyday life information literacy mind-set: A review of literature. Journal of Documentation, 73(4), 634-665.

McLennan, K. (1967). The manager and his job skills. Academy of Management Journal, 10(3), 235-245.

Moll, L. C., Amanti, C., Neff, D., \& Gonzalez, N. (1992). Funds of knowledge for teaching: Using a qualitative approach to connect homes and classrooms. Theory Into Practice, 31(2), 132-141.

Molnar, A. Huerta, L., Shafer, S. R., Barbour, M. K., Miron, G., Gulosino, C. (2015).

Virtual schools in the U.S. 2015: Politics, performance, policy, and research evidence. National Education Policy Center. http://nepc.colorado.edu/publication/virtual-schools-annual-2015; http://www.centerononlinelearning.res.ku.edu/wpcontent/uploads/ParentReport3_SocSkills_Feb2018Update.pdf

Ortiz, K., Smith, S., Rice, M., \& Mellard, D. (2017). Roles and responsibilities of parents of online school students with disabilities. Center on Online Learning and Students with Disabilities. http://www.centerononlinelearning.res.ku.edu/wpcontent/uploads/2017/05/ParentReport1_April2017.pdf 
Parsippany-Troy Township Schools. (2020). Distance learning parent survey data.

https://pthsd.k12.nj.us/UserFiles/Servers/Server_27012/File/For\%20ParentsStudents/covid19/Par entSurveyResults.pdf

Rice, M. (2015). A rhetorical perspective of parental role construction of online learning testimonials. In M. Rice (Ed.), Exploring pedagogies for diverse learners online (pp. 117-137). Emerald Group Publishing.

Rice, M., \& Carter, Jr., R. A. (2015). When we talk about compliance it's because we lived it: Online educators' experiences supporting students with disabilities. Online Learning, 19(5), 1836. https://files.eric.ed.gov/fulltext/EJ1085761.pdf

Rice, M., \& Deschaine, M., (2021). We need to help teachers withstand public criticism as they learn to teach online. In R. E. Ferdig, \& K. Pytash (Eds.), What teacher educators should have learned from 2020 (pp. 101-110). Association for the Advancement of Computing in Education (AACE). https://www.learntechlib.org/p/219088/

Rice, M., \& Ortiz, K. (2020). Perceptions of accessibility in online course materials: A survey of teachers from six virtual schools. Journal of Online Learning Research, 6(3), 245-264. https://www.learntechlib.org/primary/p/217628/

Rice, M., Ortiz, K., Curry, T., \& Petropoulous, R. (2019). A case study of a foster parent working to support a child with multiple disabilities in a virtual school. Journal of Online Learning Research, 5(2), 145-158. https://www.learntechlib.org/p/184933/

Rice, M., Ortiz, K., Smith, S., \& Mellard, D. (2017). Parents' perceptions of social/emotional support for their children with disabilities in fully online schools. Center on Online Learning and Students with Disabilities. http://www.centerononlinelearning.res.ku.edu/wpcontent/uploads/ParentReport3 SocSkills Feb2018Update.pdf

Schultz, A. J. (2019). Why parents of students with disabilities enrolled their child in an online virtual charter school: Using extant data [Doctoral dissertation]. California State Polytechnic University, Pomona. https://scholarworks.calstate.edu/downloads/rj430670m

Smith, S., Rice, M., Ortiz., K., \& Mellard, D. (2017). Parents' perceptions of special education service delivery when their children move to fully online learning. Center on Online Learning and Students with Disabilities. http://www.centerononlinelearning.res.ku.edu/wpcontent/uploads/2017/05/ParentReport2_IEP_April2017.pdf

Sorensen, C. (2012). Learning online at the K-12 level: A parent/guardian perspective. International Journal of Instructional Media, 39(4), 297-308.

Street, B. V., \& Street, B. B. (1984). Literacy in theory and practice (Vol. 9). Cambridge University Press. 
Tonks, D., Kimmons, R., \& Mason, S. L. (2021). Motivations among special education students and their parents for switching to an online school: survey responses and emergent themes. Online Learning, 25(2), 171-189.

Trainor, A. (2013). Interview research. In A. Trainor and E. Graue (Eds.), Reviewing qualitative research in the social sciences (pp. 125-138), Routledge. van Joolingen, W. (2004). The PISA framework for assessment of ICT literacy [Powerpoint slides]. https://www.slideshare.net/cristobalcobo/the-pisa-framework-for-assessment-of-ictliteracy

Webber, S., \& Johnston, B. (2017). Information literacy: Conceptions, context and the formation of a discipline. Journal of Information Literacy, 11(1), 156-18.

Yamauchi, L. A., Ponte, E., Ratliffe, K. T., \& Traynor, K. (2017). Theoretical and conceptual frameworks used in research on family-school partnerships. School Community Journal, 27(2), 9-34. 